\title{
NEWS INFOCUS
}

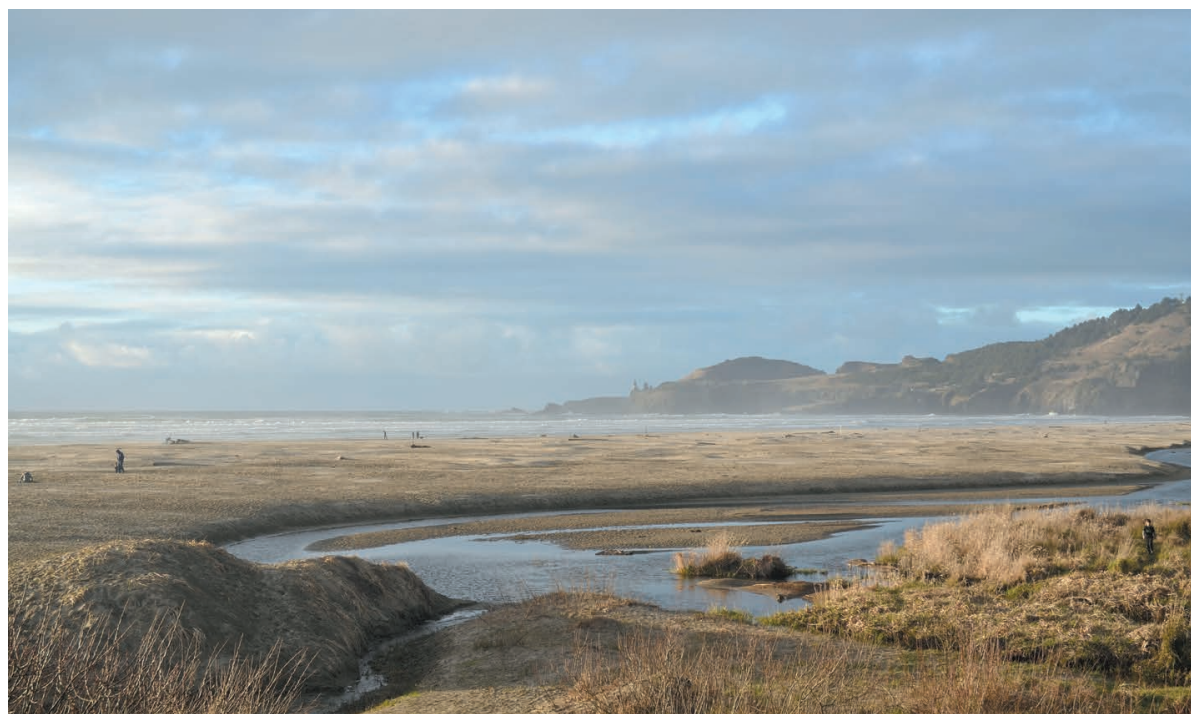

Tidal wetlands such as this marsh in Oregon can store large amounts of carbon.

Agriculture (USDA) showed more variation, but those figures were based on data collected by people who were often thinking more about agriculture on land. In the Mississippi delta, for instance, many early measurements were limited to surface sediments that are rich in carbon, and estimates of the soil density below the surface may have been too high. As a result, Windham-Myers says, the USDA
But understanding how much carbon is in the ground is just a prelude to determining the rate at which wetlands sequester carbon. That figure depends in part on local topography and on the rate at which seas rise and create more space for carbon-rich sediments to accumulate. And methane emissions vary widely depending on whether water in a wetland is salty, fresh or brackish. Similarly, understanding how much carbon enters the atmosphere when a wetland is drained for agriculture or other purposes requires a more detailed understanding of the soil make-up. All of this information must be plugged into models to project how wetlands will evolve in the coming decades.

Crooks hopes that providing better data on the carbon stored by wetlands will encourage governments to halt the destruction of these ecosystems. "It's important that we find every mechanism that we can to offset our carbon emissions," Crooks says. "This is one piece of the puzzle."

overestimated carbon stocks in the region.

Crooks says that if soil measurements from wetlands elsewhere agree with the US findings, global estimates of carbon stocks could improve. Windham-Myers and her colleagues recently examined data from coastal wetlands across Africa, and the results were consistent with the team's analysis of cores from US tidal wetlands.

\section{CORRECTION}

The image of the eclipse in 'Images of the year' (Nature 552, 308-313; 2017) was an artistic representation that did not accurately depict the event. It has been replaced with a new image online. 